\title{
Cross-Sectional Study on Knowledge, Attitude and Practice of Voluntary Blood Donation among Nursing Staff at Orotta National Referral Teaching Hospital Asmara, Eritrea
}

\author{
Elias Teages Adgoy ${ }^{1 *}$, Michael Solomon², AwetGhebretinsae², Kebire Girmay²,Danait \\ Fissehaye $^{2}$, Zekarias Andemariam ${ }^{3}$ \\ 1 Department of Community Medicine and Primary Health Care, Orotta College of Medicine and Health Sciences, Asmara, Eritrea \\ 2 Ministry of Health, Asmara, Eritrea \\ 3 Mai-Nefhi College of Sciences, Asmara, Eritrea
}

*Corresponding Author: Dr. Elias Teages Adgoy, Department of Community Medicine and Primary Health Care, Orotta College of Medicine and Health Sciences, Asmara, Eritrea.

Email: eliasteages@gmail.com

Received: February 01, 2021; Accepted: March 11, 2021

\begin{abstract}
Introduction: Blood transfusion is one of the essential components of quality health care service package. Safe blood for transfusion is obtained mainly from Voluntary blood donors that are considered as safe contributors of blood and blood components. even though the level of knowledge, attitude and beliefs regarding blood donation affects the number of potential voluntary blood donors, in emergency situations the availability and accessibility of safe blood and blood products is crucial; Objective: The aim of this study was to assess the knowledge, attitude and practice towards voluntary blood donation among nursing staff and to determine the association between blood donation, and gender, age and educational or professional level of nursing staff.Methodology: A cross-sectionalstudy on knowledge, attitude, and practice of voluntary blood donation among nursing staff was conducted at Orotta National Referral and Teaching Hospital (ONRTH), Asmara, Eritrea. In this study a total of 142 nursing staff were recruited. A structured questionnaire was applied to collect information. Data was cleaned, coded, entered and analyzed using SPSS version 22. Results: The study included a total of 142 nursing staff that had three professional levels. Majority (67.6\%) of the study participants were females with a Mean age of 26.99 years $(S D \pm 6.643)$. About $78 \%$ and $94 \%$ were Orthodox by religion and Tigrigna ethnic group, respectively. Majority $(100 \%, 93.7 \%)$ of the studyparticipant had good knowledge on blood groups/types and their blood group and Rh. Almost $99 \%$ and $75 \%$ had awareness on age group permitted to donate blood and blood donation interval of 3 months. The study results revealed an average knowledge on blood donation of people with chronic non - communicable diseases but good knowledge on the harmfulness and unsafely of blood drawing from people with communicable diseases mainly Hepatitis $(97.9 \%)$ and HIV/AIDs (99.3\%). Around $92 \%$ and $56 \%$ of the study participants responded that pregnant and lactating women cannot donate blood. Nearly Sixty five percent of the respondents noted that blood drawing at once/single time should not exceed $500 \mathrm{ml}$ and either within the time interval of less or 20 minutes (36.6\%), or 20 minutes to 1 hour (35.2\%). Majority(94.4\%) of the respondents agreed that blood donation as good and voluntary donors as the best $(90.1 \%)$ where as $78.2 \%$ mentioned also patients relatives blood donation as a replacement donation. Temporary weakness (77.5\%) was as the main complication that can happen during and after blood donation. Around half ( $55 \%$ ) of the nursing staff have never donated blood and the main reason for not donating blood was underweight (57\%). About $68 \%$ of those who donated blood $44.4 \%$ were voluntarily blood donors less than once(93.7\%) in a year. The study revealed a significant association between blood donation and male gender ( $P$-value $=0.001)$, but age $(P$-value $=0.384)$ and nursing staff educational or professional level $(P$-value $=0.721)$ were found to have no significant association.Discussion and conclusion: The study results revealed a good knowledge and attitude towards blood donation. But the level of practice in donating blood was found to be very low.Significant association between male gender and blood donation was found. But age and educational or professional level were found to have no significant association with blood donation. Therefore, the study recommends to Ministry of Health, higher teaching institutions (medical school and college of health sciences) and the national blood bank to design policies and strategies that promote and motivate students and health service staff members in donating blood and pivoting the communities towards voluntary blood donation.
\end{abstract}

Keywords: Hydatid cyst, Lung, Pregnancy. 


\section{INTRODUCTION}

Safe blood transfusion is one of the essential components of quality health care service package. The amount of blood that is used for transfusion is collected from healthy individuals in the age range of $18-60$ years. Voluntary blood donors are the main contributor of safe blood to be transfused. Sufficient and safe blood donation/transfusion service is an essential component of health care system of a nation. Those who are selected for blood donation should be from a group of population with low risk of infection and prevalence of infectious diseases.

In the low-income developing countries malaria, multiparty, pregnancy and delivery, traffic accidents and injuries increase the magnitude of the demand for blood transfusion needs. In most of the developing world especially Sub-Saharan countries the largest amount of blood is transfused to children and mothers.

According to World Health Organization (WHO), survey Report (2010), out of the 46 countries of the WHO African Region, in 2010 forty-three countries had collected a total of 3, 486, 192 units of blood that ranged from 942 units (Equatorial Guinea, population $=700401$ ) to 789 units (South Africa, population number $=50,132,817)^{[1]}$.

As a result of the advancement in clinical sciences, population increase and rise in traffic accidents, the need for blood donation and transfusion is growing. Blood donation is one of the genuine human acts that help in saving lives, because blood is an essential element of human life without an ideal substitute. According to $\mathrm{WHO}$ (2013), the average blood donation rate in the African region was 4.7 units/1000 inhabitants ranging from $0.7 / 1000$ in Nigeria to $39.7 / 1000$ in Mauritius ${ }^{[2]}$.

In developing countries although many individuals are aware about blood donation andare eligible to donate blood only a small percentage of eligible individuals donate blood ${ }^{[2]}$. In most developing countries hesitation for blood donation is attributed to misconceptions related to fear of physical harm during donation $[3,4]$

World Health Organization advocates for 100 percent of nonremunerated voluntary blood donation (VBD), which is considered as the first line defense against transmission of diseases. In the African region still the average percentage of voluntary non-remunerated blood donors (VNRBD) is $67.0 \%$.But in South Sudan it ranges from $2.3 \%$ to $100 \%{ }^{[2]}$. In Eritrea in 2010 , blood donation rate was 2.8 units / 1000 population and $88 \%$ were voluntary donors, whereas in 2013 it was observed to be lowered to 1.4 units /1000 population for blood donation rate and $92.5 \%$ voluntary donors ${ }^{[1,2]}$.

Blood donation is one of the most important practices for saving life and maintaining health of individuals. This is usually promoted by creating awareness among health professionals and proper community health education and sensitization. A cross sectional study that was conducted in three medical colleges of Karachi (2014), documented 92\%of appropriate knowledge regarding blood donation with $50 \%$ willingness of donating blood among the students ${ }^{[5]}$. Reports froma crosssectional study on knowledge, misconceptions and motivations towards blood donation among university students that was conducted in Saudi Arabia (2013), indicated $81 \%$ of the study participants as non-donors and those who were donors had an experience of $13 \%, 5 \%$ and $1 \%$, donation of blood for once, twice and regularly, respectively. The study also mentioned friends (53\%) and television (TV) (24\%) as the most common channels or sources of information for the study participants regarding blood donation ${ }^{[6]}$.

A study on the assessment of knowledge, attitude and practice of voluntary blood donation among healthcare workers that was conducted in Nigeria (2013), documented a good knowledge with positive attitude towards voluntary blood donation but poor practice of voluntary blood donation. The study reported $22.1 \%$ of blood donation among health workers of whom only $41.7 \%$ were voluntarily. The study showed as a strong disparity between the knowledge, attitude, and practice of voluntary donation amongst healthcare workers ${ }^{[3]}$.

In East African countries there are many studies on voluntary blood donation. A study on knowledge, attitudes, practices, and associated factors with voluntary blood donation among university students in Tanzania (2016), reveled $93 \%$ of positive attitude and 88 percent of willingness to blood donation. The study also showed a significant association between ever donating blood, and male gender, knowing a person who donated blood, willingness to donate, the amount of blood to be donated, and not expecting reward after donation ${ }^{[7]}$. According Ahmed (2017), a study on knowledge, attitude, practice and associated factors of voluntary blood donation among undergraduate students in Hargeisa university also reported inadequate knowledge (46.6\%) and favorable attitude (46.9\%). The study also indicated a significant association between blood donation, and age and male gender [8].

A study in Ethiopia, by Teklu (2015), reported a good knowledge on blood donation in $54.2 \%$ among health workers ${ }^{[9]}$. Another community based cross-sectional study in Ethiopia (2016), also revealed an adequate knowledge, good attitude and experience of blood donation as $56.8 \%, 82 \%$ and $18.4 \%$, respectively. The study also found a significant association between adequate knowledge towards blood donation, and increased level of education, age, self-perceived health status and religion [10]. A study on knowledge, attitude and practice towards blood donation and associated factors among adults in Northwest Ethiopia (2016), documented $56.5 \%$ and $52.2 \%$ of knowledge and favorable attitude on blood donation, respectively ${ }^{[11]}$.

\section{Study objectives}

The aim of this study was to assess the knowledge, attitude and practice towards voluntary blood donation among nursing staff and to determine the association between blood donation, and gender, age, and educational or professional level of nursing staff.

\section{METHODOLOGY}

\section{Study design and Study area}

A cross-sectional quantitative descriptive study was conducted at Orotta National Referral and Teaching Hospital (ONRTH), located in the capital city, Asmara, Eritrea.

\section{Study participants}

The study participants were Nurses with Bachelor's Degree (BSc.N), Diploma Nurses and Associate Nurses with certificate. 


\section{Sample selection and sample size}

First, nursing staff were listed according to their professional/educational level by stratifying in to three categories. Secondly, a systematic random sampling was applied for each professional category for the purpose of inclusion $50 \%$ of the source population.

\section{Data collection and analysis}

Data was collected by the research team using a structured questionnaire through face-to-face interview. Data was analyzed using descriptive statistics like frequency, percentage, mean, standard deviation and association of the variables was tested through Chi-square test. Data editing was performed on site immediately after data collection for checking accuracy, consistency and missed values. The collected data was entered in to excel software which was later exported to SPSS version 22 for data cleaning and analysis.

\section{RESULTS}

\section{Socio-demographic characteristics of study participants}

The study included a total of 142 nursing staff with three different levels of nursing professions out of which $6(4.2 \%)$ nurses with Bachelor's Degree (BSc.N), 66 (46.5\%) midwife nurses (Nurses with Diploma) and70 (49.3\%) associate nurses (certificate). Majority $(67.6 \%)$ of the study participants were females, and the age range was between 21-60yearswith a mean age of 27 years (SD \pm 6.6 ). Almost $78 \%$ of the study participants were Orthodox by religion and from Tigrigna ethnic group (93.7\%) (Table 1).

Table 1: Socio-demographic characteristics of study participants $(\mathrm{N}=142)$

\begin{tabular}{|c|c|c|c|}
\hline \multicolumn{2}{|c|}{ Variable } & Number (N) & Percent (\%) \\
\hline \multicolumn{4}{|c|}{ Gender } \\
\hline & Male & 46 & 32.4 \\
\hline & Female & 96 & 67.6 \\
\hline \multicolumn{4}{|c|}{ Age } \\
\hline & $20-29$ Years & 115 & 81.0 \\
\hline & $30-39$ Years & 20 & 14.1 \\
\hline & $\geq 40$ Years & 7 & 4.9 \\
\hline \multicolumn{4}{|c|}{ Religion } \\
\hline & Orthodox & 113 & 79.6 \\
\hline & Muslim & 11 & 7.7 \\
\hline & Catholic & 10 & 7.0 \\
\hline & Protestant & 8 & 5.6 \\
\hline \multicolumn{4}{|c|}{ Ethnic group } \\
\hline & Tigrigna & 133 & 93.7 \\
\hline & Tigre & 6 & 4.2 \\
\hline & Hidareb & 2 & 1.4 \\
\hline & Saho & 1 & 0.7 \\
\hline \multicolumn{4}{|c|}{ Marital status } \\
\hline & Married & 16 & 11.3 \\
\hline & Widowed & 2 & 1.4 \\
\hline & Living Together & 1 & 0.7 \\
\hline & Single & 123 & 86.6 \\
\hline \multicolumn{4}{|c|}{ Educational or Professional level } \\
\hline & Associate Nurse $(12+1)$ & 70 & 49.3 \\
\hline & Midwife Nurse $(12+3)$ & 66 & 46.5 \\
\hline & Nurses with Bachelor's Degree $(12+4)$ & 6 & 4.2 \\
\hline
\end{tabular}

\section{Knowledge on blood donation}

All (100\%) participants of the study were found to be familiar with the types of blood group but $6.3 \%$ of the study participants didn't knew their blood group or Rh. Almost all (99.3\%) and $74.6 \%$ of nursing staff were aware of the age group permitted to donate blood and blood donation interval of 3 months, respectively (Table 2). 
Table 2: Knowledge on blood donation ( $\mathrm{N}=142)$

\begin{tabular}{|c|c|c|}
\hline \multicolumn{2}{|c|}{ Variable } & $\mathbf{N}(\%)$ \\
\hline \multicolumn{3}{|c|}{ Knowledge on blood groups or types } \\
\hline & Yes & $142(100 \%)$ \\
\hline & \multicolumn{2}{|l|}{$\begin{array}{l}\text { Number of nursing staff who know their } \\
\text { blood group or type }\end{array}$} \\
\hline & yes & $133(93.7 \%)$ \\
\hline & No & $9.0(6.3 \%)$ \\
\hline \multicolumn{3}{|c|}{ Blood group of the respondent } \\
\hline & $\mathrm{A}$ & $27(19.0 \%)$ \\
\hline & B & $37(26.1 \%)$ \\
\hline & $A B$ & $11(7.7 \%)$ \\
\hline & $\mathrm{O}$ & $58(40.8)$ \\
\hline & Don't know their blood group & $9.0(6.3 \%)$ \\
\hline & \multicolumn{2}{|l|}{ Rh of the respondent } \\
\hline & $\mathrm{Rh}^{+\mathrm{ve}}$ (Rh Positive) & $127(89.4 \%)$ \\
\hline & $\mathrm{Rh}^{-\mathrm{ve}}$ (Rh Negative) & $6.0(4.2 \%)$ \\
\hline & Don't know their RH group & $9.0(6.3 \%)$ \\
\hline \multicolumn{3}{|c|}{$\begin{array}{l}\text { How often can an individual donate for a } \\
\text { blood }\end{array}$} \\
\hline & Monthly & $9.0(6.3 \%)$ \\
\hline & Every Three Months & $106(74.6 \%)$ \\
\hline & Every Six Months and above & $17(12.0 \%)$ \\
\hline & I don't Know & $10(7.0 \%)$ \\
\hline & \multicolumn{2}{|l|}{ Who Should donate blood } \\
\hline & Men and Women & $140(98.6 \%)$ \\
\hline & I don’t Know & $2.0(1.4 \%)$ \\
\hline & \multicolumn{2}{|l|}{ The optimum age for blood transfusion } \\
\hline & $\leq 18$ years & $1.0(0.7 \%)$ \\
\hline & $18-60$ years & 141 (99.3\%) \\
\hline
\end{tabular}

Out of all the respondents $54.2 \%, 51.4 \%, 59.2 \%$ and $90.8 \%$ mentioned that blood donation from patients with diabetes, hypertension, mental illness and disability (non - communicable diseases) as bad or harmful procedure to the donors. Majority (97.9\% and $99.3 \%$ ) of the study participants also mentioned that blood donation from donors with hepatitis and HIV/AIDs (communicable diseases) as insalubrious procedure and unsafe. Thirteen percent of the respondents were not able to identify the minimum weight of a person who should donate blood. Around $92 \%$ and $56 \%$ of the study participants responded that a pregnant and lactating woman cannot donate blood, respectively, whereas the remaining $4.2 \%$ and $19.0 \%$ reported that they don't have an idea on it. Almost sixty five percent of the respondents noted the maximum volume of blood drawing at once/single time should not exceed $500 \mathrm{ml}$, whereas $23.9 \%$ and $4.9 \%$ replied that $500-1000 \mathrm{ml}$ and greater than $1000 \mathrm{ml}$. and nine $(6.3 \%)$ acknowledged their lack of knowledge by stating "I do not know". As to the duration or interval of blood donation the results showed equal response $(36.6 \%$ and $35.2 \%)$ for less or equal to 20 minutes and between 20 minutes to 1 hour, whereas $28.2 \%$ acknowledged their lack of knowledge by stating "I don't know". (Table 3).
Table 3: Knowledge on blood donation regarding to diseases $(\mathrm{N}=142)$

\begin{tabular}{|c|c|c|}
\hline \multirow{2}{*}{\multicolumn{2}{|c|}{$\begin{array}{l}\text { Variable } \\
\begin{array}{l}\text { Does patients with such diseases donate } \\
\text { blood }\end{array}\end{array}$}} & \multirow[t]{2}{*}{$\mathbf{N}(\%)$} \\
\hline & & \\
\hline & Diabetes & \\
\hline & Yes & $65(45.8 \%)$ \\
\hline & No & $77(54.2 \%)$ \\
\hline & Hepatitis & \\
\hline & Yes & $3.0(2.1 \%)$ \\
\hline & No & $139(97.9 \%)$ \\
\hline & Hypertension & \\
\hline & Yes & $69(48.6 \%)$ \\
\hline & No & $73(51.4 \%)$ \\
\hline & HIV/AIDs & \\
\hline & Yes & $1.0(0.7 \%)$ \\
\hline & No & $141(99.3 \%)$ \\
\hline & Disability & \\
\hline & Yes & $13(9.2 \%)$ \\
\hline & No & $129(90.8 \%)$ \\
\hline & Mental IIIness & \\
\hline & Yes & $58(40.8 \%)$ \\
\hline & No & $84(59.2 \%)$ \\
\hline & Weight range for safe blood donation & \\
\hline & $<50$ & $19(13.4 \%)$ \\
\hline & $50-60$ & $122(85.9 \%)$ \\
\hline & $\geq 60$ & $1.0(0.7 \%)$ \\
\hline & Can a pregnant women donate blood & \\
\hline & Yes & $5.0(3.5 \%)$ \\
\hline & No & $131(92.3 \%)$ \\
\hline & I don't Know & $6.0(4.2 \%)$ \\
\hline & Can a lactating women donate blood & \\
\hline & Yes & $35(24.6 \%)$ \\
\hline & No & $80(56.3 \%)$ \\
\hline & I don't Know I don't Know & $27(19.0 \%)$ \\
\hline & $\begin{array}{l}\text { What is the amount of blood is collected } \\
\text { at a single time }\end{array}$ & \\
\hline & $\leq 500 \mathrm{ml}$ & $92(64.8 \%)$ \\
\hline & $500-1000 \mathrm{ml}$ & $34(23.9 \%)$ \\
\hline & $\geq 1000 \mathrm{ml}$ & $7.0(4.9 \%)$ \\
\hline & I don't know & $9.0(6.3 \%)$ \\
\hline & What is the duration of donation process & \\
\hline & $\leq 20$ minutes & $52(36.6 \%)$ \\
\hline & 20 minutes -1 hour & $50(35.2 \%)$ \\
\hline & I don't know & $40(28.2 \%)$ \\
\hline
\end{tabular}




\section{Attitude towards blood donation}

Out of the 142 study participants 134 (94.4\%) responded that blood donation as good and $90.1 \%$ presented voluntary donors as the best. The study results showed a response of $45.1 \%$, $52.8 \%$ and $2.1 \%$, as yes, no and I don't know for the harm fullness of blood donation. Majority $(77.5 \%)$ indicated temporary weakness as the main complication that can happen during and after blood donation. Around $78 \%$ indicated that patients' relatives blood donation is best if it is considered as a replacement donation (Table 4).

Table 4: Attitude of study participants towards blood donation $(\mathrm{N}=142)$

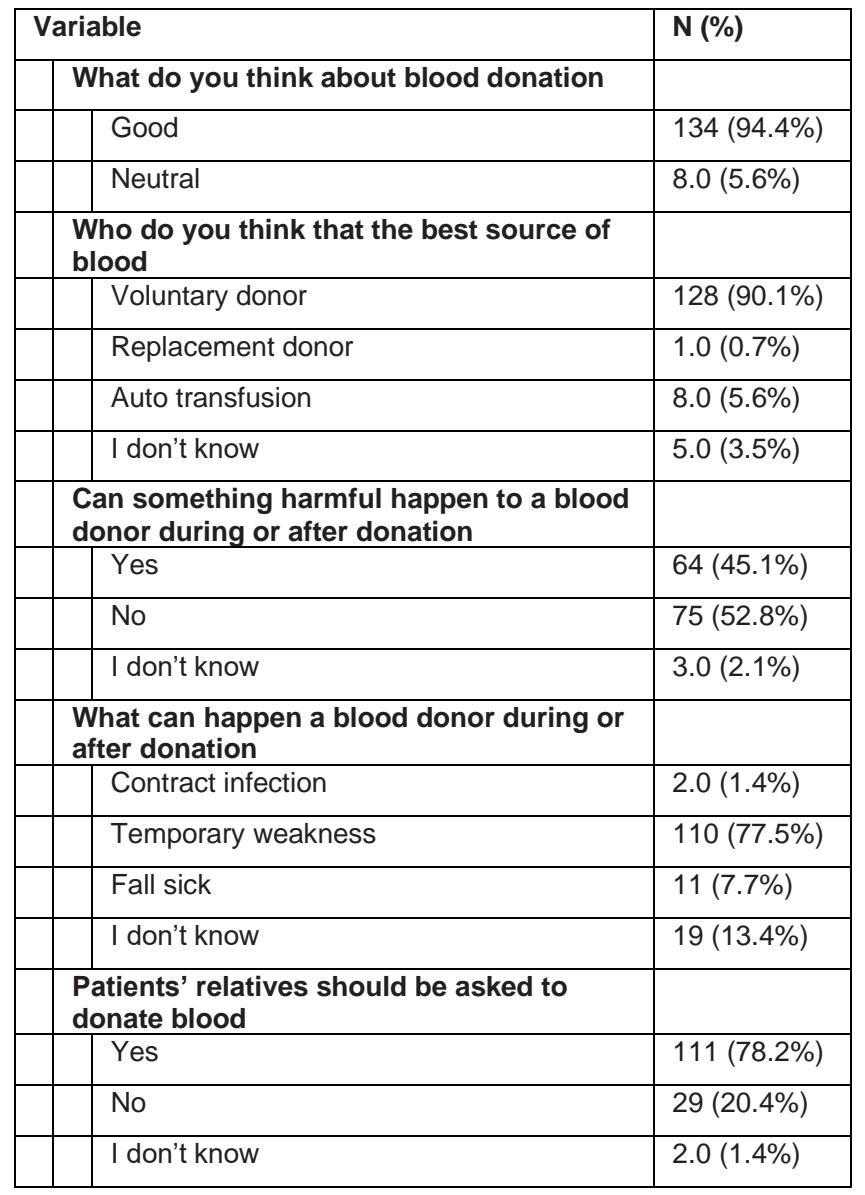

\section{Practice of blood donation}

Seventy-nine $(55.6 \%)$ of the study participants have never donated blood and the main reason for not donating blood was underweight (57.0\%). Majority (93.7\%) of those who donated blood (44.4\%) were voluntarily blood donors, but $68.3 \%$ had an experience of less than once a year. $83.1 \%$ of the study participants showed their preparedness for blood donation whenever they are reminded or called upon for blood donation (Table 5).
Table 5: Practice of study participants towards Blood Donation $(\mathrm{N}=142)$

\begin{tabular}{|c|c|c|}
\hline \multicolumn{2}{|c|}{ Variable } & $\mathbf{N}(\%)$ \\
\hline \multicolumn{3}{|c|}{ Have you ever donated blood before } \\
\hline & Yes & $63(44.4 \%)$ \\
\hline & No & $79(55.6 \%)$ \\
\hline \multicolumn{3}{|c|}{ If you didn't donate what was the reason } \\
\hline & Health problem & $7.0(8.9 \%)$ \\
\hline & Fear & $10(12.7 \%)$ \\
\hline & Under weight & $45(57.0 \%)$ \\
\hline & No reason & $17(21.5 .0 \%)$ \\
\hline \multicolumn{3}{|c|}{ If you donated how often was it } \\
\hline & $\leq$ one time a year & $43(68.3 \%)$ \\
\hline & One to three times a year & $13(20.6 \%)$ \\
\hline & More than three times a year & $7.0(11.1 \%)$ \\
\hline \multicolumn{3}{|c|}{ Why do you donate blood } \\
\hline & For a friend or relative & $4.0(6.3 \%)$ \\
\hline & Voluntary & $59(93.7 \%)$ \\
\hline \multicolumn{3}{|c|}{$\begin{array}{l}\text { If you called upon or reminded to do so, do } \\
\text { you donate blood }\end{array}$} \\
\hline & Yes & $118(83.1 \%)$ \\
\hline & No & $14(9.9 \%)$ \\
\hline & I don't know & $10(7.0 \%)$ \\
\hline
\end{tabular}

Association between blood donation and, gender and professional staff category

The study showed a significant association between male gender and blood donation $(P$-value $=0.001)$, butage and nursing staff educational or professional level were found to have no significant association with blood donation at $P$-value $=$ 0.384 and $P$-value $=0.721$, respectively (table 6).

Table 6: Association between blood donation and, gender and staff category $(\mathrm{N}=142)$

\begin{tabular}{|c|c|c|c|c|}
\hline Variable & $\begin{array}{l}\text { Donors } \\
\mathrm{N}(\%)\end{array}$ & \begin{tabular}{|l} 
Non donors \\
$\mathrm{N}(\%)$
\end{tabular} & $x^{2}$ & P- Value \\
\hline \multicolumn{5}{|l|}{ Gender } \\
\hline Male & $30(65.2 \%)$ & $16(34.8 \%)$ & \multirow[t]{2}{*}{11.985} & \multirow[t]{2}{*}{0.001} \\
\hline Female & $33(34.4 \%)$ & $63(65.6 \%)$ & & \\
\hline \multicolumn{5}{|l|}{ Age } \\
\hline $20-29$ & 49 (42.6\%) & $66(57.4 \%)$ & \multirow[t]{2}{*}{0.757} & \multirow[t]{2}{*}{0.384} \\
\hline$\geq 30$ & $14(51.9 \%)$ & $13(48.1 \%)$ & & \\
\hline \multicolumn{5}{|c|}{ Educational/ professional Level } \\
\hline \begin{tabular}{|l|} 
Associate \\
Nurses $(12+1)$
\end{tabular} & $30(42.9 \%)$ & $40(57.1 \%)$ & \multirow[t]{2}{*}{0.127} & \multirow[t]{2}{*}{0.721} \\
\hline $\begin{array}{l}\text { Diploma Nursing } \\
\text { and BSc. }(\geq 12+3)\end{array}$ & $33(45.8 \%)$ & $39(54.2 \%)$ & & \\
\hline
\end{tabular}




\section{DISCUSSION}

The study included a total of 142 nursing staff that has three educational and professional levels of which $67.6 \%$ were females. The age range was $21-60$ years with a mean age of 26.99 years $(S D \pm 6.643)$. The study participants were mainly from the Tigrigna ethnic group (93.7\%) and Orthodox (79.6\%) by religion.

This study results showed $100 \%$ knowledge on being familiar with the blood group classification/type, whereas6.3\% were found without knowledge either on their blood group and Rh. This study results are better than the study results in Ethiopia (2015 and 2018), that documented $97.6 \%$ and $96.3 \%$ good knowledge of the common blood group types and $84.1 \%$ knowledge of their own blood group and $\mathrm{Rh}{ }^{[9,12]}$. The good knowledge on the blood group classification/type can be argued that they are health professionals who are working in the hospital but the lack of knowing their blood group may be interlinked to the non-donating behaviors of these health professionals. $99.3 \%$ of the nursing staffs were aware of the age group permitted to donate blood. This study results were found in line to a study in India (2015), that showed $90 \%$ and $48.9 \%$ of knowledge about the recommended age and interval of blood donation [13]; but it was found to be inconsistent with results of a study in India (2012 and 2013) that was conducted for the assessment of awareness on blood donation among medical students (MBBS) and among the nursing staff that reported a prevalence of $43.2 \%$ and $43.18 \%$ lack to awareness of the age groups who are legitimate for blood donation [14, 15]. The study also indicated $38.63 \%$ lack of knowledge and $29.54 \%$ lack of awareness regarding to the minimum weight required for blood donation and blood donation interval of 3 months, which are inline to this study results that showed $14.1 \%$ lack of knowledge about the optimum weight required for blood donation but $74.6 \%$ of awareness regarding to blood donation interval of 3 months [15]. Majority of the study participants had a good knowledge on blood donation regarding to the people with communicable disease (Hepatitis and HIV/AIDs) but less knowledge for those with non-communicable diseases that include mainly diabetes, hypertension, mental illness and disability.

Most $(94.4 \%)$ of the study participants revealed blood donation as good and $90.1 \%$ acknowledged voluntary blood donation as the best. $52.8 \%$ of the study participants agreed that blood donation as a non-harmful procedure which is consistent to the study among health professionals, university of Gondar Hospital, Ethiopia (2017), that documented a response of $56.3 \%$ as a comfortable or positive feeling after donating blood ${ }^{[16]}$. The study results showed a response of $45.1 \%, 52.8 \%$ and $2.1 \%$, as yes, no and I don't know for the harmfulness of blood donation. Majority $(77.5 \%)$ indicated temporary weakness as the main complication that can happen either during or after blood donation. $78.2 \%$ of the nursing staffs supported relatives blood donation as a replacement.

Seventy-nine (55.6\%) of the nursing staff have not donated blood atall and the main reason for not donating blood was underweight $(57.0 \%)$. Majority $(68.3 \%)$ of those who donated blood $44.4 \%$ were voluntarily blood donors, but $93.7 \%$ had an experience of less than once a year. $83.1 \%$ of the study participants showed their preparedness for blood donation whenever they are reminded or called upon for blood donation. Even though the response of blood donation (44.4\%) is better than a study on community assessment of knowledge, attitude and practice on blood donation in South West, Ethiopia (2015), that documented a good knowledge (76\%) and positive attitude (93.8\%), and only $26.4 \%$ of blood donation in their life; it is considered to be insufficient because the study participants are health professional ${ }^{[17]}$.

The study results showed a significant association between male gender and blood donation $(P$-value $=0.001)$. These results are in line to a previous study that was conducted in Karachi (2014) and Ethiopia (2017) among undergraduate medical students, Ethiopia (2015) among health workers in Tikur Anbessa hospital and health workers in health facilities(2015), and Tanzania (2016)among university students, showed a significant association between knowledge on blood donation and male gender which in turn affects blood donation behavior $[5,7,8,9,18]$; But age $(P$-value $=0.384)$ and nursing staff educational or professional level $(P$-value $=0.721)$ were found to have no significant association with blood donation.

\section{CONCLUSION}

The study results revealed a good knowledge and attitude towards blood donation; but the level of practice in donating blood was found to be very low. The study results also showed a significant association between male gender and blood donation. But age and nursing staff educational or professional level were found to have no significant association with blood donation. Therefore, the study recommends to Ministry of Health, higher teaching institutions (Medical School and College of Health Sciences) and the National Blood Bank to design policies and strategies that promote and motivate students and health service staff members in donating blood and pivoting the communities towards voluntary blood donation.

\section{Ethics approval and consent to participate}

Ethical approval was obtained from the ministry of Health, Ethical and Research Committee and consent of participation was obtained from the study participants.

\section{Consent for publication}

All participants gave an oral and/or written consent for their information to be used in this manuscript

\section{Availability for data and material}

The data that support the findings of this study are available with the authors and can be provided upon reasonable request.

\section{Conflict of interest}

The authors declare that there is no conflict of interest

\section{Funding}

The research was funded by the research team.

\section{Acknowledgements}

We would like to thank for the study participants who provided us the required relevant information.

\section{Abbreviations: \\ AIDs Acquired Immunodeficiency Diseases Syndromes \\ BSc.N Bachelor's in the Science of Nursing \\ HIV Human Immunodeficiency Virus \\ MBBS Bachelor of Medicine, Bachelor of Surgery,}


ONRTH Orotta National Referral and Teaching Hospital

Rh Rhesus factor

SD Standard Deviation

SPSS Statistical Package for Social Sciences

TV Television

VBD Voluntary Blood Donation

VNRBD Voluntary Non Remunerated Blood Donors

WHO World Health Organization,

\section{REFERENCES}

1. World Health Organization. Status of Blood Safety in the WHO African Region: Report of the 2010 Survey, 2010.

2. World Health Organization. Current status on blood safety and availability in the WHO African Region-report of the 2013 survey. WHO. Regional Office for Africa. 2017.

3. Nwogoh B, Aigberadion U, Nwannadi Al. Knowledge, attitude, and practice of voluntary blood donation among healthcare workers at the University of Benin Teaching Hospital, Benin City, Nigeria. Journal of blood transfusion, 2013.

4. Olubiyi SK, Babalola FR, Olubiyi MV, Umar NJ, Ibraheem MA. Knowledge, attitudes and practices of blood donation among adults in Ado-Ekiti, Nigeria. Sky Journal of Medicine and Medical Sciences, 2014; 2(7):052-057.

5. Ahmed Z, Zafar M, Khan AA, Anjum MU, Siddiqui MA. Knowledge, attitude and practices about blood donation among undergraduate medical students in Karachi. Journal of Infectious Diseases and Therapy, 2014.

6. Baig M, Habib H, Haji AH, Alsharief FT, Noor AM, Makki RG. Knowledge, misconceptions and motivations towards blood donation among university students in KSA. Pakistan journal of medical sciences, 2013; 29(6):1295.

7. Elias E, Mauka W, Philemon RN, Damian DJ, Mahande MJ, Msuya SE. Knowledge, attitudes, practices, and factors associated with voluntary blood donation among university students in Kilimanjaro, Tanzania. Journal of blood transfusion, 2016.

8. Abdu AO, Teshome G, Melese DM, Girma A, Daniel K, Agizie A. Knowledge, attitude, practice and associated factors of voluntary counseling and testing for HIV/AIDS among Wolkite university students in Ethiopia. Journal of AIDS and HIV Research, 2017; 9(5):98-105.

9. Teklu S. Knowledge, attitude, practice and associated factors of blood donation among health care workers in tikur anbessa specialized hospital, addis ababa, ethiopia (doctoral dissertation, department of emergency medicine, college of health sciences, addis ababa university), 2015.

10. Melku M, Terefe B, Asrie F, Enawgaw B, Melak T, Tsegay YG, Shiferaw E. Knowledge, attitude, and practice of adult population towards blood donation in Gondar Town, Northwest Ethiopia: a community based cross-sectional study. Journal of blood transfusion, 2016.

11. Jemberu YA, Esmael A, Ahmed KY. Knowledge, attitude and practice towards blood donation and associated factors among adults in Debre Markos town, Northwest Ethiopia. BMC hematology, 2016; 16(1):23.

12. Tadesse W, Ayalew Y, Yisma E, Liben ML, Wudu M. Knowledge, Attitude, Practice and Associated Factors towards Voluntary Blood Donation among Regular Health Science Students of Samara University, Ethiopia. Health Science Journal, 2018; 12(1).

13. Chopra D, Jauhari N. Knowledge attitude \& practices towards voluntary blood donation among medical students in Barabanki. Indian Journal of Community Health, 2015; 27(3):386-390.

14. Devi HS, Laishram J, Shantibala K, Elangbam V. Knowledge, attitude and practice (KAP) of blood safety and donation. Indian Medical Gazette, 2012; 1:1-5.

15. Rao PS, Saha D, Rao ST, Chakraborti S, Adiga D. Awareness on blood donation among the nursing staff. International Journal of Advanced Research, 2013; 1(7):610-616.

16. Arage G, Ibrahim S, Adimasu E. Blood donation practice and its associated factors among health professionals of University of Gondar Hospital, Northwest Ethiopia: a cross sectional study. BMC research notes, 2017; 10(1):294.

17. Mulatu K, Hailu T, Yegezu A, Tena B. Assessment of knowledge, attitude and practice on blood donation in Aman sub city residents, South West, Ethiopia, 2015. Health Science Journal, 2017; 11(1):1.

18. Bantayehu D. Knowledge, attitude and practice of voluntary blood donation and associated factors among Health Care Providers in Addis Ababa health Facilities, Ethiopia. Occup Med Health Aff, 2015; 3(209):2. 